\title{
MODELOS ALTERNATIVOS PARA EXPLICAR LA EVOLUCIÓN DEL GASTO PÚBLICO ESPAÑOL*
}

\author{
Recibido: 17 de enero de 2019 - Aprobado: 29 de abril de 2019 \\ https://doi.org/10.22395/seec.v22n51a8 \\ Manuel Jaén García**
}

\section{RESUMEN}

El artículo contrasta empíricamente diferentes modelos alternativos, con variables tanto desde el lado de la oferta como de la demanda, para estudiar la evolución del gasto público en España en el período 1964-2016. Se utiliza la metodología habitual de raíces unitarias y cointegración en series temporales para contrastar los modelos, utilizando como base modelos de retardo distribuido autorregresivo para el largo plazo y modelos de corrección de errores para el corto. De los tres modelos considerados, el que mejor explica el comportamiento del sector público español es el modelo de hacienda pública al que se le ha añadido la variable explicativa de la burocracia.

\section{PALABRAS CLAVE}

Gasto público; modelo de hacienda pública; modelo de elección pública; modelo de administración pública; raíces unitarias; cointegración.

\section{CLASIFICACIÓN JEL}

H1 1, H50, E62

\section{CONTENIDO}

Introducción; 1. El gasto público español en el período 1964-2016; 2. Modelos de determinantes del gasto público; 3. Contrastaciones empíricas; 4. Conclusiones; Bibliografía.

Este artículo forma parte del proyecto de investigación La senda del gasto público en España: un nuevo enfoque, que ha sido financiado por el Instituto de Estudios Fiscales (Ministerio de Economía y Hacienda de España).

* $\quad$ Licenciado en Matemáticas, Universidad de Granada, Granada, España. Licenciado en Ciencias Económicas y Empresariales, Universidad de Málaga, Málaga, España. Doctor en Ciencias Económicas y Empresariales, Universidad de Granada, Granada, España. Catedrático de Economía Aplicada, Universidad de Almería, Almería, España. Director del Grupo de Investigación Avances en Economía Aplicada, Departamento de Economía y Empresa, Universidad de Almería, Almería, España. Correo electrónico: mjaen@ual.es 


\title{
ALTERNATIVE MODELS TO EXPLAIN THE EVOLUTION OF SPANISH PUBLIC SPENDING
}

\begin{abstract}
To study the evolution of public spending in Spain during 1964-2016, this article empirically contrasts different alternative models, with variables from both the supply and demands sides, The usual methodology of unit roots and cointegration in time series is used to contrast models, using as a basis autoregressive distributed delay models for the long term and error correction models for the short term. Of the three models that were taken in account, the one that best explains the behavior of the Spanish public sector is the public finance model to which the explanatory bureaucracy variable has been added.
\end{abstract}

\section{KEYWORDS}

Public spending; public finance model; public choice model; public administration model; unit roots; cointegration

\section{JEL CLASSIFICATION}

H1 1, H50, E62

\section{CONTENT}

Introduction; 1. Spanish public spending during 1964-2016; 2. Models of public spending determinants; 3. Empirical contrasts; 4. Conclusions; Bibliography.

\section{MODELOS ALTERNATIVOS PARA EXPLICAR A EVOLUÇÃO DO GASTO PÚBLICO ESPANHOL}

\section{RESUMO}

Este artigo contrasta empiricamente modelos alternativos, com variáveis tanto do lado da oferta quanto do da procura, para estudar a evolução do gasto público na Espanha de 1964 a 2016. Utilizase a metodologia habitual de raízes unitárias e cointegração em séries temporais para comparar os modelos, tendo como base modelos de retardo distribuído autorregressivo para o longo prazo e modelos de correção de erros para o curto. Dos três modelos considerados, o que melhor explica o comportamento do setor público espanhol é o modelo de finanças públicas ao qual se agregou a variável explicativa da burocracia.

\section{PALAVRAS-CHAVE}

Gasto público; modelo de finanças públicas; modelo de eleição pública; modelo de administração pública; raízes unitárias; cointegração.

\section{CLASSIFICAÇÃO JEL}

$$
\text { H11, H50, E62 }
$$

\section{CONTEÚDO}

Introdução; 1 . O gasto público espanhol de 1964 a 2016; 2. Modelos de determinantes do gasto público; 3. Comparações empíricas; 4. Conclusões; Bibliografia. 


\section{INTRODUCCIÓN}

Es un hecho probado el incremento de la ratio GP/PIB (gasto público/producto interno bruto) en España en períodos recientes, tanto en términos nominales como reales. En trabajos anteriores se han ensayado diversos modelos explicativos de esta evolución del gasto, gran parte de ellos a través de modelos bivariantes, tales como la ley de Wagner. El propósito de este artículo es construir modelos de determinantes de la evolución del gasto público en los que, a diferencia de otros publicados anteriormente, se consideren determinantes, tanto desde el lado de la oferta como desde la demanda, lo que permite formular diferentes explicaciones alternativas del gasto público y realizar su contrastación empírica. Para cumplir con este propósito, este trabajo se basa en Gemmell, Gill y Nguyen (2016) que, a su vez, consideran una larga tradición en cuanto a posibles determinantes del gasto público, las que se van abordando a lo largo del artículo. Aunque se consideran tres modelos diferentes, el mejor ajuste para explicar la evolución del gasto público es un modelo de hacienda pública al que se le añade la variable representativa de la burocracia.

En el siguiente apartado se considera la evolución del gasto público en España en los últimos años y las diferentes etapas que se pueden distinguir en la misma. En el tercero se presentan los diferentes aspectos teóricos y en el cuarto se realiza la contrastación empírica de los diferentes modelos. Por último, en el quinto se presentan las conclusiones del trabajo.

\section{EL GASTO PÚBLICO ESPAÑOL EN EL PERÍODO 1964-2016}

Se han desarrollado diferentes medidas del papel del Estado en la economía, tanto desde el lado del ingreso como desde el gasto. En este apartado se considera, por una parte, el gasto público en relación con el PIB y, por otra, el empleo público, incluyendo en este el total de las administraciones públicas españolas (central, autonómica y local).

En el período de estudio, esto es, 1964-2016, se pueden distinguir seis fases diferentes de acuerdo con la naturaleza del gasto público español. Por una parte, el periodo predemocrático 1964-1975, en el que el gasto público en España se mantuvo por debajo del $20 \%$ del PIB en la primera parte (19,5\% en 1965), a diferencia del resto de países de la futura Unión Europea $15^{1}$ (33,1 \%) y de la Organización de Cooperación y Desarrollo Económico (OCDE) (26,9\%), y lo supera ligeramente en la parte final

La UE15 se constituyó tras la cuarta ampliación de la UE (anteriormente Comunidad Económica Europea) en 1995. La formaban los países fundadores: Alemania, Francia, Italia, Luxemburgo y los Países Bajos más Reino Unido, Irlanda y Dinamarca (a partir de 1973), Grecia (1981), España y Portugal (1986) y Austria, Finlandia y Suecia (1995) 
(24,1 \% en 1975) aunque en ese momento en el área Euro era del 40,9\% y en la OCDE del $34,4 \%$. El número de empleados públicos al inicio del periodo era muy bajo, 716.000 en la administración pública y 122.000 en las empresas públicas incluidas en el Instituto Nacional de Industria (INI). Esto corresponde al 7,23 \% de todos los asalariados y $4,8 \%$ de la población trabajadora. Dada la naturaleza centralizada del Estado, muchos empleados públicos pertenecen a la administración central y solo un pequeño porcentaje a la administración local. Para la segunda fase, en 1975, el número de empleados públicos era 1.280.282 lo que representa el 10,1 \% del total del empleo con 222.038 en el Instituto Nacional de Industria (INI). A pesar de la fuerte subida, España estaba por debajo del promedio de los países de la OCDE (16,1 \%) y de los países desarrollados (Alemania con 13,9\%, Dinamarca con 23,6 \% o Estados Unidos con $18 \%$.

La intervención del Estado en la economía se produce a través de la regulación, en forma de leyes y reglamentos. En los años 60, la industrialización ayudó al crecimiento del gasto público. En la tradición de Wagner, el desarrollo económico fue de la mano con un aumento en población, urbanización, vivienda, educación, salud y redistribución del ingreso.

En el período de 1975 a 1985 se produce un rápido crecimiento del gasto público español que se puede, a su vez, dividir en dos etapas. En la primera, entre 1975 y 1982, se produce un intenso crecimiento en el gasto público con una tasa anual acumulativa del 25,5\% que se puede atribuir a tres factores según Alcaide (1988): la transición política, la manifestación de las consecuencias más graves de la crisis económica y la existencia de los gobiernos débiles de Unión del Centro Democrático (UCD) y la fuerte oposición del Partido Socialista Obrero Español (PSOE). En la segunda etapa, aunque continua el crecimiento con una tasa acumulativa anual del 15,3\%, el crecimiento es menor debido a diversos factores entre los que destaca una menor virulencia de la crisis económica y, sobre todo, la entrada en una fase de recuperación de la economía desde mediados de 1985, existencia de una mayoría absoluta del partido gobernante y un régimen democrático consolidado. Considerando esta etapa en su totalidad, hay consenso entre diversos especialistas en que las causas fundamentales de la evolución expansiva del gasto público en este periodo fueron: i) el cambio de régimen político y los pactos de transición, ii) la crisis económica iii) la persistencia del déficit y su nueva financiación en condiciones de mercado, iv) la descentralización de ciertas funciones de gasto sin la correlativa cesión de responsabilidad fiscal a las comunidades autónomas y v) la laxitud presupuestaria.

La expansión del gasto público trajo consigo un significativo aumento en el empleo público. En 1985 representaba el 17,7 \% del empleo total, mientras los empleos 
en las administraciones públicas alcanzaban el 13,4\%, en línea con Estados Unidos $(15,8 \%)$ y Alemania (16,1 \%), pero por detrás del promedio de la OCDE (19,3\%). En ese año 38,4 \% de esos empleos corresponden a la administración central, 17,9 \% a la seguridad social, $21,6 \%$ a las comunidades autónomas (CCAA) y 22,4 \% a la Administración Local (AL). En el año 1985 se empieza a producir el proceso de privatización de muchas compañías públicas pertenecientes al INI, lo que afectó a diferentes sectores y, especialmente, a muchas pequeñas y medianas empresas que no eran viables en sectores que fuesen realmente competitivos. Este cambio marcó la reducción del número de empleados en el sector público industrial (211.000 en 1984, 152.000 en 1985). Al mismo tiempo, la crisis causó una subida en el desempleo. Para mitigar la amenaza de desempleo masivo se ofreció a los trabajadores de muchas empresas en crisis la posibilidad de jubilación anticipada.

La tercera etapa -entre 1986 y 1993- es una de las más importantes de nuestra historia reciente, pues comienza con la entrada de España en la Comunidad Económica Europa y finaliza con la puesta en marcha del primer programa de convergencia. En 1993, el gasto público representaba un 49,6 \% del PIB. Como afirma Valle (1996) no existe ninguna experiencia cercana de países en los que, en tan solo veinte años, la proporción del gasto público total, no financiero, se haya duplicado prácticamente, así, en este período de tiempo se ha seguido con absoluta fidelidad la ley de Wagner. Al mismo tiempo, se ha ido consolidando el estado de las autonomías, con lo que la gestión de ese enorme crecimiento del gasto ha ido recayendo en unas administraciones públicas que se están poniendo en marcha en esos momentos, lo que une a su falta de experiencia el trasvase de competencias. Afirma Valle (1996) que buena parte de los males de la hacienda española derivan de la falta de modernización que el aumento del gasto y su cambio de estructura hubieran exigido para la adecuada gestión y control del gasto público.

En esta fase, el crecimiento del gasto público derivó en gran parte de la política sobre el Estado de bienestar del gobierno socialista. Se amplió para todos los españoles la cobertura del sistema sanitario y creció el número de pensionistas mediante las pensiones no contributivas, así como la cuantía de dichas pensiones. El aumento en el número de alumnos en el sistema educativo obligatorio, así como en la educación superior hizo aumentar el gasto en educación. Se puede utilizar el mismo argumento con respecto al sistema privado de educación, al que se le aumentaron las subvenciones pues muchos colegios privados pasaron a formar parte del sistema concertado ${ }^{2}$. Con la consolidación de la España de las autonomías, el Estado inicia una fuerte expansión en el gasto con deterioro del equilibrio presupuestario.

En el sistema concertado, la administración de la educación es privada, pero su financiación es mayoritariamente pública. 
En la última fase de este período la necesidad absoluta de cumplir las condiciones fijadas en el Acuerdo de Maastricht ${ }^{3}$ produjo una reducción del déficit, después de alcanzar su valor más elevado, en el período, en relación al PIB (5,9\%).

Como resultado de los cambios y tendencias señalados anteriormente, se produce una gran subida en el empleo público durante el período. Gran parte del empleo se creó en los sectores sanitario y educativo, pero una parte importante correspondió a la transferencia de trabajadores de la administración central a las comunidades autónomas, de tal forma, no solo se absorbieron dichos trabajadores, sino que además se crearon nuevos puestos de trabajo. En 1986, el empleo público alcanzó 2.000.000 de trabajadores, de los cuales 360.000 pertenecían a las CCAA y 170.500 a las empresas públicas, lo que suponía un 18 \% del empleo total. En 1993 este total alcanzó 2.212.000, de los que 598.500 pertenecían a las CCAA y 77.547 a las empresas públicas, lo que supone un 18,1 \% del empleo total. Esta evolución está inicialmente unida a la creación de empleo en las CCAA Debido, fundamentalmente, a la asunción de competencias procedentes del gobierno central. El mismo fenómeno se produjo en las administraciones locales que aumentaron de 342.700 a 394.100 empleados. Este aumento fue compensado por la disminución del empleo en las empresas públicas. Disminución provocada, fundamentalmente, por el proceso de privatización que tuvo lugar en ese período. Las empresas públicas fueron completamente privatizadas, como fue el caso de la Sociedad Española de Automóviles de Turismo (SEAT) o parcialmente como ocurrió con Energía y Celulosa (ENCE) y Repsol ${ }^{4}$, aunque el sector público siguió teniendo el control sobre algunas de las empresas más importantes tales como Telefónica y la Empresa Nacional de Electricidad Sociedad Anónima (Endesa).

En la cuarta etapa, 1994-2000, el gobierno español aceptó las condiciones del Tratado de Maastricht lo que significó, inicialmente, que España tendría que ajustar su gasto, así que, tanto el déficit como la deuda, deberían reunir las condiciones del acuerdo, y segundo, que tendría que cumplir en su totalidad el pacto de estabilidad y crecimiento.

En el período entre 1994 y 1998 se producen los siguientes acontecimientos: i) descentralización fiscal, ii) reorganización del sector público empresarial, iii) revisión de la normativa relacionada con las prestaciones sociales. Este período se caracteriza por el desarrollo de una estrategia de consolidación fiscal que adquirió mayor firmeza a partir de 1996, y permitió cumplir con el criterio de déficit público

\footnotetext{
3 Es el tratado que sustenta la integración europea, pues al modificar los tratados de París y de Roma se sobrepasa la mera unidad económica y se le da una vocación de unidad política.

4 Es una multinacional energética y petroquímica española. Repsol es uno de los pocos nombres de empresas que no obedece a unas siglas o a esa obsesión castiza.
} 
fijado en el Tratado de Maastricht y romper la tendencia alcista del endeudamiento público en un contexto de recuperación económica.

A partir de 1996 se produce un fuerte viraje en el sector público español. Este responde, en forma conceptual, a un cambio de paradigma económico desde el modelo socialdemócrata postkeynesiano al neoclásico-liberal. Las razones más inmediatas para este cambio hay que buscarlas en el cumplimiento de las condiciones de Maastricht, en el cumplimiento del Pacto de Estabilidad y Convergencia y en la coincidencia del período que se inicia en 1996 con la fase ascendente del ciclo económico. En este período, el objetivo prioritario fue el saneamiento de las finanzas públicas para cumplir los criterios de convergencia. Los elevados déficits presupuestarios (7,3 \% del PIB en 1994) cayeron al 2,6 \% en 1998, cumpliendo estrictamente con las condiciones del pacto de estabilidad con respecto a los déficits presupuestarios ( 3 \% del PIB). La consolidación de la recuperación económica a lo largo de 1994, el aumento del empleo, la corrección del desequilibrio exterior, la moderación salarial y los avances conseguidos en la reducción de la inflación y del déficit público fueron los resultados más significativos de la política gubernamental.

El número de empleados públicos permaneció bastante estable en alrededor del 18 \% del empleo total, aunque en 1998 bajó al 16,3 \%. En 1995 se creó la Sociedad Estatal de Participaciones Industriales (SEPI), el holding de industrias propiedad del Estado, absorbiendo Repsol y el grupo Teneo que estaba compuesto por las participaciones públicas en empresas con beneficios tales como Endesa, Iberia y Aviaco. El proceso de privatización continuó con la venta de acciones de Enagas ( $9 \%$ ), Endesa ( $56 \%$, después de las privatizaciones en períodos previos), Telefónica (21\%) y Repsol (10\%).

La quinta fase es el período entre 2001 y 2007, que representó una etapa de consolidación de las finanzas públicas en España y que estuvo inicialmente basado en la burbuja inmobiliaria que hizo posible un crecimiento sin precedentes en la economía española. Así en 2001 se equilibró el presupuesto con un gasto público del $40 \%$ del PIB. El empleo público en 2001 era de 2.566.000 trabajadores, lo que representa un 15,3\% del empleo total y, al final del período, es prácticamente de 3 millones, lo que equivale a un 14,3 \% del total de la economía. Se creó empleo por parte de las CCAA y las administraciones locales debido al proceso de asunción de nuevas competencias del Estado, asimismo, el empleo puede ser creado por iniciativa propia. El número de empleados en la administración central se mantuvo prácticamente constante (561.000 en 2001 frente a 559.300 en 2006), mientras las CCAA, lo aumentaron de 903.100 a 1.284.000, y las AL de 551.000 a 589.000. En cuanto a las empresas públicas debe decirse que estas emprendieron un proceso 
de privatización que provocó su transferencia al sector privado en empresas tales como la Red Eléctrica Española (Red de alto voltaje), CASA (aviación civil), Transmediterránea (transporte marítimo) y Argentaria (banco público).

Por último, de 2008 a 2016 se produce una implosión de la economía española, comenzando por la explosión de la burbuja inmobiliaria. Inicialmente, continuó la expansión y el PIB español alcanzó la media de la UE $27^{5}$. En ese momento la economía española, alineada con las economías europeas y estadounidense y con sus propios problemas internos, entra en una severa recesión de la que empieza a emerger actualmente con algún crecimiento positivo del PIB (en 2014 1,4 \% y 3,3 \% en 2016) y con elevados déficits presupuestarios (5,97\% en 2014, 5,28 \% en 2015 y $4,51 \%$ en 2016).

El estallido de la burbuja inmobiliaria tuvo ciertas repercusiones en el empleo público en forma de congelación salarial e, incluso, disminución de los salarios de los funcionarios. Además, bajo estas circunstancias, no se crearon nuevos empleos y las vacantes producidas debido a muertes o jubilaciones no fueron cubiertas. Había 3.081.600 empleados públicos en 2008, el número cayó a 2.986.100 en 2016, aunque se observa mejor la disminución considerando que en 2011, momento en que se repercute en el empleo público gran parte del peso de la burbuja, había 3.234.700 y con valores por debajo de los tres millones en 2013 y 2014. La repercusión de esa bajada se produjo en todas las administraciones públicas a partir de 2011 y, aunque en 2016 se empieza a recuperar el empleo, este no ha vuelto a alcanzar en ninguna de ellas las cifras de 2001, lo que significa que se perdieron alrededor de 50.000 empleos en las administraciones autonómicas, 80.000 en las administraciones locales y 80.000 en la administración central. Con relación a las empresas públicas, continuando la privatización de grandes y pequeñas compañías o muy pequeños porcentajes de acciones de las mayores del grupo SEPI, el número de empleados permaneció prácticamente constante en 154.000. Incluso, aunque el gasto público actual en España ha crecido con relación a períodos anteriores, hay una diferencia con respecto al resto de países europeos de la OCDE. En 1960, la ratio con relación al PIB era del 19,8\%, mientras en otros países era del 29,5\% y, en el total de la OCDE, el porcentaje era del 26,6\%. En menos de treinta años, las ratios eran UE27, 46,1 \%, UE15, 50,9\% y OCDE 41,1 \%. En estos momentos las ratios son UE27, 48,1 \%, UE15, $49,2 \%$, OCDE 41,2 \% y España 43,6\%.

El siguiente gráfico resume las reflexiones anteriores. El cuadro de la izquierda nos muestra la evolución, entre 1964 y 2016 del gasto público con respecto al PIB en

En 2004 se incorporaron a la UE la República Checa, Chipre, Eslovaquia, Eslovenia, Estonia, Hungría, Letonia, Lituania, Malta y Polonia, y en 2007 Rumania y Bulgaria. 
euros constantes del año 2000 y, el de la derecha, la evolución del empleo público durante el mismo período.

Gráfica 1. Gasto público en relación al PIB en términos reales y empleados del sector público
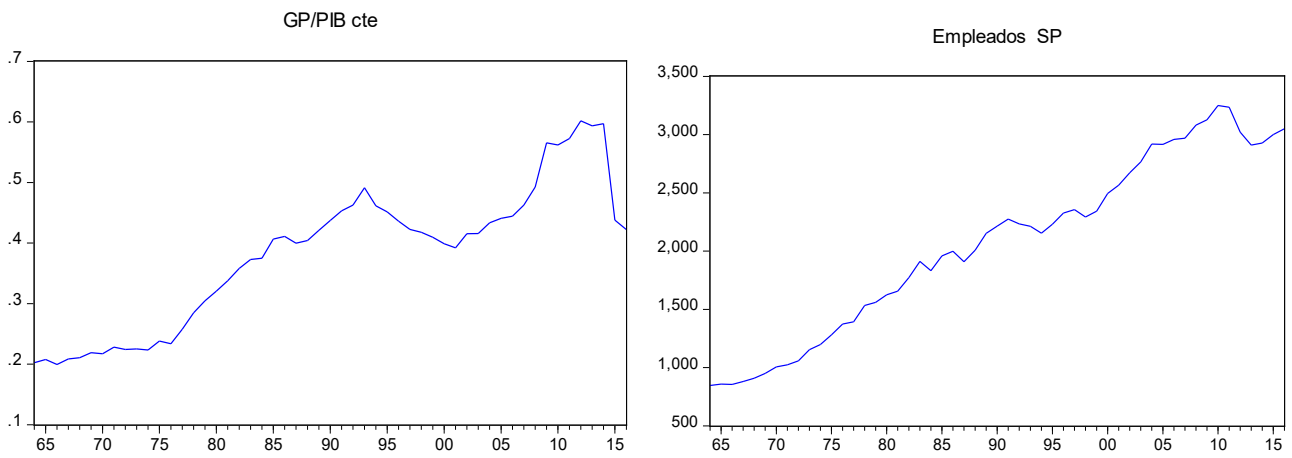

En el gráfico de la izquierda en el eje de abscisas se considera el tiempo y en el eje de ordenadas el cociente entre el gasto público y el PIB. En el de la derecha en el eje de ordenadas se considera el número de empleados públicos en miles.

Fuente: elaboración propia con datos de Instituto Nacional de Estadística (INE) y la Fundación BBVA.

\section{MODELOS DE DETERMINANTES DEL GASTO PÚBLICO}

Este trabajo, en la línea de Gemmell et al. (2016), considera tres diferentes aproximaciones a los determinantes del tamaño del sector público español. Por una parte, la literatura sobre hacienda pública, en segundo lugar, la denominada elección pública y, por último, la literatura de administración pública. Las dos primeras comprenden variables que se pueden considerar tanto desde el lado de la oferta como desde la demanda.

La aproximación de hacienda pública considera los gastos públicos como análogos a los gastos familiares en bienes producidos de manera privada. Es decir, el gasto público refleja la demanda familiar para bienes provistos públicamente, tomando la forma de una función de demanda del consumidor convencional, en la cual la renta familiar, los precios relativos y otras características específicas de la familia determinan la demanda para el bien en cuestión (Gemmell, 1990, 1993; Cullis y Jones, 2009). En el caso de los bienes ofertados vía gasto público (es decir, gratis en el punto de consumo), los precios son medidos por alguna forma de precio impositivo al consumidor, o bien por un deflactor del gasto público. Los precios impositivos en este contexto representan la carga impositiva (marginal o promedio) asociada con la provisión pública y se aproximan corrientemente por un tipo impositivo marginal o promedio. En tales modelos, el mecanismo político por el cual 
la demanda del consumidor se convierte en acción pública se deja sin especificar o bien es implícitamente una elección del votante mediano o decisivo, mecanismo que es hecho explícito en los modelos de elección pública.

La aproximación de hacienda pública provee una ecuación de demanda del consumidor estándar para bienes ofertados públicamente en forma lineal o logarítmico lineal como la siguiente

$$
\mathrm{G}=\alpha y^{\beta} \mathrm{N}^{\gamma} p_{g}^{\varepsilon_{g}} p_{c}^{\varepsilon_{c}} Z_{\mathrm{PF}}^{\mu}
$$

Donde $\mathbf{G}$ es el output real de bien provisto públicamente, (y) es la renta per cápita, $\mathbf{N}$ es la población y $\mathbf{p}_{\mathbf{g}}$ y $\mathbf{p}_{\mathbf{c}}$ son respectivamente el precio de los bienes ofertados públicamente y un índice de precios privados. $\mathbf{Z}$ es un vector de características de las familias, sugerido por la aproximación de hacienda pública, que se supone tiene impacto en la demanda de $\mathbf{G}$. Se esperan los siguientes signos en los parámetros: $\beta$ $>1(<1)$ si la demanda para bienes provistos públicamente es, en promedio, elástica a la renta (inelástica), $\gamma=0$ si G es un bien público puro (es decir la adición de nuevos consumidores no afecta a la demanda total) y $\gamma>0$ si existe congestión o tiene otras características de bien privado. Las elasticidades precio $\varepsilon_{\mathrm{g}}$ y $\varepsilon_{\mathrm{c}}$ son, respectivamente, negativa y positiva, pues los bienes privados son, necesariamente, sustitutos de los bienes provistos públicamente en un contexto de dos tipos de bienes.

Dadas las dificultades para medir los precios implícitos de los bienes públicos, $p_{g}$, y puesto que los datos de los que disponemos son los correspondientes a los gastos públicos, $E=p_{g} G$, la ecuación 1 se puede convertir en una ecuación de gasto público de manera que el signo esperado en $\mathrm{p}_{\mathrm{g}}$ es positivo si $\varepsilon_{\mathrm{g}}>-1$. La ecuación anterior se convierte en:

$$
\mathrm{E}=\alpha y^{\beta} \mathrm{N}^{\gamma} p_{g}^{\left(\varepsilon_{g}+1\right)} p_{c}^{\varepsilon_{c}} \mathrm{Z}_{\mathrm{PF}}^{\mu}
$$

Y el término $\mathbf{p}_{\mathbf{g}}$ en el lado derecho de la ecuación puede ser recogido mediante variables proxies o reescrito como un precio relativo $\mathrm{p}_{\mathrm{g}} / \mathrm{p}_{\mathrm{c}}$. Se puede reescribir la ecuación anterior en términos relativos en la forma:

$$
\frac{\mathrm{E}}{\mathrm{PIB}}=\alpha\left(\frac{\mathrm{Y}}{\mathrm{N}}\right)^{\beta} \frac{1}{\mathrm{Y}} \mathrm{N}^{\gamma} p_{g}^{\left(\varepsilon_{g+1)}\right)} p_{c}^{\varepsilon_{c}} \mathrm{Z}_{\mathrm{PF}}^{\mu}
$$

De forma que los coeficientes $\beta-1$ e $\gamma-1$ pueden ser positivos o negativos. Esta ecuación es similar al modelo del votante-contribuyente mediano formulada por Borcherding y Deacon (1972) y Bergstrom y Goodman (1973) y utilizada, entre otros muchos, por Tridimas (1992), Courakis, Moura-Roque y Tridimas (1993) y Jaén-García (2004, 2016, 2017). La utilización de las diferentes variables puede ser justificada 
mediante diferentes teorías de crecimiento del gasto público. Así, la relación entre gasto público y crecimiento económico viene justificada por la ley de Wagner. En segundo lugar, al igual que en otras funciones de demanda (y oferta) existe un efecto precio en el caso de bienes públicos. Dado que, como se ha dicho anteriormente, esos precios no son observables, pues muchos bienes y servicios ofertados públicamente son considerados bienes públicos puros, lo que significa que el tamaño del grupo beneficiario, el porcentaje del coste de estos bienes que será financiado por el votante mediano, el coste marginal y el grado de publicidad determinan su precio para el individuo (Neck y Schneider, 1988). Sin embargo, aun cuando no haya un precio de mercado explícito para muchos servicios públicos, sí hay un precio impositivo explícito que puede contrastarse con los precios de los bienes privados. Suponiendo que no hay ilusión fiscal, un determinante clave de los precios relativos será la disparidad de costes de Baumol. Desde el lado de la oferta, la hipótesis de disparidad de costes de Baumol afirma que la innovación exógena y las diferencias en productividad entre los sectores público y privado afectan los costes relativos del trabajo de los bienes ofertados públicamente. Esto se transmite a los precios relativos de los bienes en una economía competitiva y puede por tanto ser recogido por los términos de precio en la ecuación (2). Para poder tener capacidad explicativa es necesario que la disparidad vaya unida a una demanda inelástica al precio o elástica a la renta. Por tanto, tomamos la ratio del deflactor de los gastos públicos al deflactor del consumo privado (o del PIB) como un indicador del precio relativo de los bienes públicos y privados.

La aproximación de elección pública recoge una amplia variedad de factores relacionados con la política económica basados en diversos trabajos sobre sistemas políticos, burocracias públicas, grupos de interés, etc. Una amplia discusión sobre los diferentes aspectos de esta aproximación puede verse en Mueller (2003). Se consideran varias hipótesis desde el lado de la demanda y desde el lado de la oferta. Desde el lado de la demanda (la escuela de Chicago de la elección pública) el Estado se siente restringido por, o está respondiendo a, las demandas o a las preferencias de los votantes. Es decir, el Estado usa los gastos públicos y los impuestos para canalizar las demandas de los votantes expresadas a través del proceso electoral. La motivación para esas demandas incluye la provisión de bienes públicos, la eliminación de externalidades y el deseo de redistribución de renta y riqueza. En tales modelos, el gobierno responde a los deseos del ciudadano o votante mediano o grupo de interés particular de votantes sobre cuyas preferencias pivotan los resultados electorales. Meltzer y Richard $(1978 ; 1981 ; 1983)$ argumentan que el crecimiento del Estado se fomenta por la competencia para conseguir los votos y por la redistribución de la renta. En su búsqueda de votos, los políticos proponen muchos más programas de 
los que pueden llevar a cabo. Cada miembro del electorado compara los beneficios que espera recibir de los programas de expansión del gobierno con los costes que espera pagar. Los votantes escogerán a los candidatos que prometan actuar en su interés y reelegirán a aquellos que lo hacen. Con sufragio universal, y dado que el votante mediano tiene una renta por debajo de la renta promedio, él y todos los que se encuentran en la misma situación pueden salir ganando si se gravan las rentas por encima de la media y se transfieren los ingresos obtenidos a los que están por debajo de ella. De ese modo, los gobiernos con un gran gasto público son consecuencia de la diferencia entre la distribución de votos y la distribución de la renta. El gobierno crece cuando el sufragio se extiende para incluir más votantes por debajo de la renta mediana (el votante decisivo), cuando el crecimiento de la renta le proporciona ingresos para aumentar la redistribución y cuando la distribución de la renta se hace más desigual, pero las grandes redistribuciones también tienen un coste en que reducen los incentivos para trabajar y ahorrar. Este coste será soportado por todos en alguna medida y, por tanto, constituye un freno -débil- del crecimiento del gobierno.

El gobierno crecerá porque hay una diferencia decisiva entre los procesos políticos y de mercado. El mercado produce una distribución de la renta menos igualatoria que la distribución de votos, así que aquellos con renta menor usarán el proceso político para conseguir programas de redistribución de renta en su propio favor. Los políticos tienen un incentivo para atraer votantes con rentas cercanas a la mediana ofreciendo beneficios que imponen un coste neto en aquellos con rentas por encima de la mediana. El programa redistributivo ofrecido varía de lugar a lugar y de tiempo en tiempo, cuando la composición del electorado cambia. Pero el apoyo para la redistribución continuará mientras el desincentivo para trabajar, ahorrar e invertir no disminuya la renta futura lo suficiente para convertir las ganancias esperadas en una pérdida.

En segundo lugar, se toma en cuenta la redistribución para grupos de interés fuertes. Las sociedades están divididas en muchos estratos, dando lugar a grupos de gente que tienen intereses en común en una determinada cuestión. La gente suele agruparse sobre la base de su renta relativa o, más frecuentemente, de su posición en la división del trabajo o de otras características personales o sociales. El número de grupos y su importancia se asocia normalmente con la creciente especialización de la economía, el nivel de renta, la disminución de los costes de información y transacción, la amplitud de los mercados no competitivos y el proteccionismo.

El Estado puede suministrar bienes privados a determinados grupos y repartir sus costes entre toda la población. Esos grupos presionan a los poderes públicos 
para conseguir la provisión o denegación de ciertos beneficios. Es decir, constituyen el vehículo transmisor de las presiones que se ejercen sobre el gobierno. Dado que la población no tiene una apreciación ajustada de los costes o beneficios de un programa, los costes pueden estar muy repartidos y no guardar relación directa con el programa, y los beneficios pueden sobreestimarse. De esta forma cada grupo puede articular demandas para conseguir impuestos menores y mayores subsidios para una parte de la sociedad. La satisfacción de cada grupo cuesta relativamente poco, pues el aumento de impuestos es repartido entre todo el electorado completo, pero le produce al partido en el poder un alto rendimiento de los votos de los grupos satisfechos. Aranson y Ordeshook (1977) muestran que son muchas las situaciones en las que el Estado puede seguir suministrando bienes privados, aunque sus costes sean superiores a sus beneficios. El resultado se podría modelar como un dilema del prisionero con $n$ personas. Todos los grupos de interés podrían preferir que nadie obtenga su bien privado de manos del Estado, más no por ello dejarían de estar motivados para presionar en favor del bien que desean, y que, por lo tanto, les sería suministrado.

Aunque la existencia de grupos de presión no es per se un factor de expansión del sector público, hay, sin embargo, imperfecciones en el mercado político (tales como diferencias en los costes de información, transacción y de presión para diferentes grupos) que permiten la formación de coaliciones para extraer recursos para su beneficio exclusivo. De esta forma, en un momento dado, el tamaño del gobierno es un producto de la competencia entre grupos para conseguir el dinero gubernamental. Entre los factores que determinan la fuerza de un grupo está, en primer lugar, el número de individuos en el grupo. Así, grupos socioeconómicos amplios, que tienen un gran número de miembros, es probable que tengan una fuerte influencia en los gastos públicos. Es el caso, por ejemplo, de las necesidades médicas y de ayuda pecuniaria de la población jubilada o de los jóvenes que demandan políticas públicas en favor de sus necesidades educacionales o de los desempleados que, igualmente, son un grupo socioeconómico de amplio tamaño que demanda una fuerte atención de los políticos. Tales grupos socioeconómicos a través de sus demandas de políticas públicas influyen sobre el tamaño del gobierno. Además, pueden cambiar el tamaño del gasto público a lo largo del tiempo. Por ejemplo, un aumento de la población de la tercera edad, incluso manteniendo constante la demanda para asistencia médica y pensiones de jubilación, provocaría necesariamente un aumento del tamaño del gobierno. Análogamente ocurriría con una subida relativa de la población de jóvenes o desempleada ${ }^{6}$.

Utilizando estas aproximaciones se obtienen ecuaciones similares a la (2), donde la renta relevante, los precios y las características del voto se refieren específicamente

Lowery y Berry (1983) incluyen estas variables entre las derivadas de la ley de Wagner. 
al votante mediano o decisivo (Jaén-García, 2017). También se ha utilizado como proxy para las preferencias del votante, más o menos inclinadas a la redistribución, la ideología del partido en el gobierno.

Desde el lado de la oferta (escuela de Virginia de la elección pública) se supone implícitamente que el Estado está por encima de los ciudadanos. Se consideran tres explicaciones. En primer lugar, el reconocimiento del problema principal-agente entre los políticos y los burócratas en la provisión pública basado en el análisis de la burocracia de Niskanen $(1968 ; 1971)$ que lleva al argumento de que el tamaño del Estado está influido por las preferencias de burócratas, sus formas de remuneración, etc. En consecuencia, es la utilidad del burócrata, a través del presupuesto o del número de funcionarios, lo que se relaciona con el gasto público. En segundo lugar, se considera la posibilidad de que los votantes sufran ilusión fiscal debido a la falta de transparencia del proceso político para determinar las vías de financiación de los gastos públicos. Se considera que los votantes subestiman sus obligaciones fiscales en forma general o respecto a un tipo determinado de impuestos o con respecto a las obligaciones de deuda con lo que es poco probable que reaccionen a un aumento de gasto basado en alguna o todas esas posibles ilusiones. Si sufren ilusión de deuda es poco probable que voten o reaccionen contra las propuestas de aumento de gasto público financiadas mediante deuda pública.

Un tercer argumento considera el papel de la elasticidad ingreso de un impuesto o elasticidad-impuesto. La elasticidad-impuesto es el cambio proporcional en el ingreso impositivo asociado con una subida proporcional dada en la renta. En algunos modelos de elección pública del gasto público esta es una forma de ilusión fiscal. En particular, se argumenta que donde la elasticidad-impuesto es superior a la unidad se genera una subida más que proporcional en los ingresos cuando la renta nominal aumenta debido a efectos automáticos, incluso cuando no hay cambios discrecionales en el escenario impositivo. En la medida en que, los cambios impositivos discrecionales son más visibles a los votantes-contribuyentes que están asociados con el crecimiento de la renta real o la inflación, la elasticidadimpuesto puede proporcionar un proxy para la medida de ilusión fiscal asociada con ese impuesto. Fundamentalmente, este argumento es aplicable a los impuestos personales sobre la renta (IRPF) pues es donde la estructura típicamente progresiva del tipo impositivo genera una elasticidad mayor que uno. Un argumento adicional desde el lado de la elección pública es que los cambios en el gasto son políticamente más fáciles de proponer e implementar cuando el ingreso requerido es disponible automáticamente que cuando debe ser conseguido vía subidas discrecionales en los tipos impositivos o cuando se requiere nueva financiación mediante deuda. Esto puede, pero no necesariamente, representar un efecto de ilusión fiscal. Es decir, 
los votantes-contribuyentes pueden sancionar las subidas en el gasto cuando surge de ingresos generados por el crecimiento de la renta, pero no cuando requiere una subida en los impuestos pagados para niveles de renta dados. Este argumento sugiere que las medidas de elasticidad-ingreso impositivo pueden suponer un instrumento útil en la contrastación empírica del modelo de elección pública del gasto público, aunque no distinguiría los aspectos de ilusión fiscal de los aspectos de no ilusión.

Para Niskanen (1968; 1971), los empleados públicos tienen preferencias por los presupuestos grandes y el poder de monopolio sobre la producción pública y el control sobre la información de los legisladores les permiten conseguir sus objetivos. Estas preferencias por presupuestos grandes se deben a que los niveles de poder, sueldo y prestigio aumentan paralelamente con los presupuestos. Borcherding (1985) argumenta que no está claro por qué los burócratas tienen este poder redistributivo y los políticos se muestran impotentes para impedir la expansión excesiva del presupuesto. Esto hace que Borcherding, Bush y Spann (1977) intenten rescatar la proposición original de Niskanen, argumentando que los burócratas son un grupo de interés más, aunque especialmente efectivo. Presionan para conseguir que el presupuesto se expanda porque sus funciones de oferta de trabajo son menos que perfectamente elásticas cuando crece el presupuesto.

Como ha sido confirmado en varios estudios, los empleados públicos constituyen un sector del electorado favorable al mantenimiento y crecimiento del sector público. Esto hará que estén dispuestos a otorgar su voto a los políticos o a los partidos favorables al sector público. Para Bush y Denzau (1977) cuando los empleados del sector privado pasan a serlo del público, su nivel deseado de gasto público aumenta pues lo que ahora les llega no son solo los beneficios de los bienes públicos, sino también los salarios que se derivan de los gastos públicos. Conforme a una pauta cíclica, cada vez se aprobarán más gastos públicos y cada vez pasarán más votantes a ser burócratas contratados para colaborar en la ejecución de esos gastos acrecentados. Con el tiempo se llegará a un equilibrio en el que el aumento del presupuesto ya no se traducirá en un número mayor de empleados, sino en salarios mayores para los empleados existentes. Una vez estabilizado, sin embargo, el nivel de gastos resultante será muy superior al óptimo que en un principio prefería el votante mediano. La variable para contrastar empíricamente esta teoría es la tasa de empleados públicos sobre el total de empleados (Empub).

Pommerehne y Schneider (1978) definen la ilusión fiscal como la percepción errónea sistemática por parte de los individuos del volumen de la carga impositiva y de otros tributos que soportan, así como del beneficio que obtienen de los gastos públicos y sus efectos sobre las decisiones relativas al gasto público bajo diferentes 
instituciones de elección colectiva. Esta percepción errónea les lleva a subestimar el verdadero coste de los bienes y servicios públicos y así los demandan en mayor cuantía de lo que lo harían en otro caso.

La ilusión fiscal se interpreta en la literatura como una infravaloración sistemática de la carga del sujeto provocada por la visibilidad limitada de los distintos impuestos y otros ingresos públicos. De un modo general, pueden distinguirse tres causas de la visibilidad restringida de la carga fiscal (Wagner, 1976; Pommerehne y Schneider, 1978):

- El coste de la información debido a los métodos de valoración y distribución del ingreso público. Los impuestos directos, tales como el de la renta personal, son más visibles para los individuos que los indirectos. Además, el juicio sobre la carga impositiva real disminuye cuando los impuestos se pagan a través de retenciones en los salarios que cuando se pagan directamente.

- El coste de la información debido a la distribución temporal de la valoración tributaria. El contribuyente considera más gravoso pagar impuestos de una sola vez que pagarlos en pequeñas cantidades sobre una base regular. Si se produce la financiación de gastos mediante la venta de propiedades públicas o mediante deuda (lo que implica el pago de futuros impuestos), el individuo no percibe carga fiscal alguna.

- Costes de información debidos a la complejidad del sistema de ingresos. Una estructura de ingresos impositivos compleja dificulta la medición de su carga fiscal por parte de los contribuyentes.

Considerando las diferentes hipótesis de elección pública se puede formular un modelo empírico de la siguiente forma:

$$
\mathrm{E}=\alpha y_{m}^{\beta_{1}} \text { Desemp }^{\beta_{2}} \text { Partido }^{\beta_{3}} \text { Elast }^{\beta_{4}} \text { Empub }^{\beta_{5}} Z_{\mathrm{PC}}^{\mu}
$$

Donde $\mathbf{y}_{\mathbf{m}}$ representa la renta del votante mediano o decisivo, Desemp mide el tamaño o influencia de los grupos de interés específicos (desempleados en nuestro caso) que impactan en los niveles o elecciones de gasto público, Partido, puede tomar la forma de una dummy para partidos de izquierda o derecha en el poder o una medida más detallada para períodos específicos de un gobierno en particular. La variable Elast recoge la hipótesis de elasticidad impositiva comentada anteriormente. La ecuación no recoge explícitamente una variable de ilusión fiscal, aunque Elast puede recoger algunos de sus efectos. Empub recoge la influencia de la burocracia en el crecimiento del gasto. Por último, $\mathbf{Z}$ denota otras características de 
los contribuyentes, sistema democrático o burocracia asociadas con la aproximación de elección pública.

Aunque contrastar rigurosamente los argumentos de elección pública ha resultado bastante difícil en la literatura internacional existente, provee una fuente útil de amplias proposiciones relacionadas con la economía política del tamaño del sector público que se pueden explorar empíricamente junto con otras explicaciones alternativas para ver si se encuentra apoyo en el caso español.

La literatura de administración pública está separada de las anteriores y tiende a no hacer referencia a las otras aproximaciones. Es también más descriptiva de acuerdos institucionales en lugar de adoptar una metodología de establecer hipótesis y contrastarlas con los datos disponibles usando metodologías empíricas/econométricas específicas. Esto hace más difícil compararla con otras aproximaciones e incorporarla en modelos econométricos. La literatura de administración y dirección públicas considera las cuestiones de cómo el Estado se autoorganiza y cómo la forma del Estado puede estar cambiando, pero está menos centrada en explicar cambios en el tamaño del Estado per se.

La literatura pone énfasis en un cambio en la forma del Estado en diferentes países escandinavos y anglosajones de la OCDE asociados con la introducción de la nueva dirección pública. Dentro de los diferentes países se consideran diferentes etapas en los cambios que se han producido en la dirección de la economía distinguiéndose entre vieja administración pública, nueva dirección pública (NPM en sus siglas en inglés) y posnueva dirección pública de acuerdo con la introducción de nuevas leyes de reforma de la administración pública. Hood (1991) sugiere que la NPM está unida a cuatro megatendencias en el tiempo, de las cuales la primera (intentos de disminuir o revertir el crecimiento del gasto público en relación al gasto público abierto y la dotación del personal) sería contrastable con los datos de Gemmell et al. (2016). En forma similar, Pollitt (1995) propone ocho elementos nucleares de la NPM, de los cuales el primero está directamente relacionado al tamaño de los presupuestos del sector público. Esos ocho elementos son:

1) Recortar costes, limitar presupuestos.

2) Introducir mecanismos de mercado y cuasimercado (contratación exterior).

3) Desagregación de grandes departamentos en departamentos más manejables.

4) Separación de funciones.

5) Descentralización de autoridad dentro de las organizaciones. 
6) Dirección por resultados.

7) Determinación de pago local no nacional.

8) Creciente énfasis en el servicio y la calidad.

La lista de Pollitt no se pronuncia acerca de varias facetas del Estado, tales como su papel en la regulación, imposición, gasto en transferencias, privatización, dirección macroeconómica. En lugar de ello sus categorías están relacionadas con la organización del Estado mismo $(2,3,4)$ o cómo las agencias públicas dirigen los asuntos dentro de su organización (5,6,7 y 8). Sin embargo, el énfasis en recortar costes (1) sugiere que la NPM puede estar asociada con una reversión en el crecimiento del sector público, especialmente en relación con el resto de la economía.

Siguiendo las dos aproximaciones anteriores un contraste general de la NPM tendría la siguiente forma:

$$
\mathrm{E}=\alpha \mathrm{NPM}^{6_{1}} \mathrm{PNPM}^{6_{2}} \mathrm{Z}_{\mathrm{PA}}^{\mu}
$$

Donde las variables NPM y PNPM son variables dummy que toman valores de 1 en el período y 0 en otro caso. El vector $\mathbf{Z}$ representa otras variables asociadas con el modelo de administración pública o controles, tales como factores cíclicos requeridos para identificar adecuadamente los dos cambios de tendencia que se han considerado (sean los que sean). Necesariamente incluyen variables dummy de cambio o desplazamiento para los dos períodos considerados.

En el caso español se puede considerar un cambio drástico: la firma por el Estado de los acuerdos de Maastrich y el pacto de estabilidad y crecimiento con el compromiso de que la deuda pública no fuese superior al $60 \%$ del PIB y el déficit no fuese superior al $3 \%$. Este compromiso trajo consigo un recorte en el gasto público en el año 1993 y posteriores.

\section{CONTRASTACIONES EMPÍRICAS}

Utilizamos los datos correspondientes al período (1964-2016 o 1980-2016) para las diferentes variables. Las variables las tomamos en logaritmos con lo que los coeficientes son las diversas elasticidades. Dada la posible falta de estacionariedad de algunas o de todas las variables, realizamos contrastes de raíces unitarias de las mismas, cuyos resultados se reproducen en la tabla 1.

Para la estimación utilizamos un modelo de retardo distribuido autorregresivo (ARDL) parametrizado en forma de un modelo de corrección de error (ECM) para 
identificar los efectos a corto y largo plazo y la velocidad de ajuste al equilibrio. Un modelo ARDL general se puede formular en la siguiente forma:

$$
y_{t}=\sum_{j=1}^{p} \alpha_{j} y_{t-j}+\sum_{j=0}^{q} \beta_{j} \mathrm{X}_{t-j}+\varepsilon_{t}
$$

Donde el vector $\mathbf{X}$ en (5) incluye las variables independientes de interés. Se pueden realizar diferentes parametrizaciones de la ecuación anterior, pero es conveniente expresarla en forma de un modelo de corrección de error

$$
\Delta y_{t}=\rho\left(y_{t-1}-\beta \mathrm{X}_{t}\right)+\sum_{j=1}^{p-1} \alpha_{j}^{*} \Delta y_{t-j}+\sum_{j=0}^{q-1} \beta_{j}^{*} \Delta \mathrm{X}_{t-j}+\varepsilon_{t}
$$

Donde $\rho$ recoge el componente de corrección de error y $\beta$ la relación de equilibrio a largo plazo entre $\mathbf{y}$ y $\mathbf{X}$, con los efectos a corto plazo recogidos por . El término de corrección de error $\rho$ es una medida de la velocidad con la que el modelo retorna al equilibrio después de un shock. De acuerdo con diversos estudios tales como Pesaran y Smith (1995), Pesaran (1997) y Pesaran y Shin (1999), los estimadores obtenidos de una regresión OLS de un ARDL son consistentes y, en el caso de que las variables de interés sean I (1), los estimadores de los parámetros son súper consistentes.

Para seleccionar el número de retardos en los modelos ARDL atendemos a criterios de información SIC y AIC.

La aproximación de hacienda pública sugiere que los niveles agregados o promedio de renta pueden ser relacionados con la demanda para gasto público, mientras la aproximación de elección pública especifica un votante decisivo que puede o no ser el perceptor de la renta mediana. En cualquier caso, distinguir entre efectos debidos a renta media o mediana en tales ejercicios empíricos, no es posible en general. Por ello utilizamos la renta total y la renta per cápita como proxies para los efectos de demanda relacionados con la renta.

Un argumento similar se aplica al desempleo. Se usa la tasa de paro para recoger fluctuaciones en la demanda para gastos relacionados con el bienestar y otros gastos que no pueden ser adecuadamente medidos por fluctuaciones en las rentas puesto que tales gastos se mueven desproporcionadamente con las rentas. Sin embargo, esto puede reflejar un efecto de demanda convencional que surge de los cambios asociados en la distribución de la renta cuando los niveles cambian en el corto plazo, en vez del nivel de renta mismo, o recoge los efectos de las preferencias del votante para redistribución como se propone en algunos modelos de elección pública.

En el modelo de elección pública, se tiene cierta dificultad para definir el tipo impositivo promedio marginal (AMTR), por ello se ha utilizado como proxy el tipo 
impositivo medio en el impuesto sobre la renta definido como el cociente entre la cuota tributaria y la base imponible. Dado que este dato está disponible en España desde 1980, tendremos que limitar nuestro contraste empírico al período 1980-2016. En la tabla 1 se muestran los estadísticos descriptivos de las diferentes variables del modelo con el período de tiempo para el que disponemos de valores muestrales en cada caso.

Tabla 1. Estadísticos descriptivos de las variables en niveles

\begin{tabular}{lcccccc}
\hline & GP/PIB cte & DGP/DPIB & $\begin{array}{c}\text { Empleados } \\
\text { SP }\end{array}$ & PIBPC & Población & $\begin{array}{c}\text { Tasa de } \\
\text { desempleo }\end{array}$ \\
\hline Media & 0,38 & 0,98 & 2060,36 & 15704,35 & 39561,36 & 13,37 \\
\hline Mediana & 0,40 & 1,00 & 2153,00 & 15928,92 & 39460,00 & 14,36 \\
\hline Máximo & 0,60 & 1,04 & 3250,30 & 23131,63 & 46812,00 & 26,94 \\
\hline Mínimo & 0,19 & 0,76 & 846,27 & 6848,72 & 31549,00 & 0,73 \\
\hline Desviación estándar & 0,11 & 0,06 & 756,99 & 4939,88 & 4303,056 & 7,75 \\
\hline Sesgo & $-0,04$ & $-1,99$ & $-0,12$ & $-0,02$ & 0,10 & $-0,16$ \\
\hline Curtosis & 2,13 & 6,60 & 1,79 & 1,71 & 2,35 & 1,79 \\
\hline Jarque-Bera & 1,67 & 63,83 & 3,33 & 3,63 & 1,01 & 3,44 \\
\hline Probabilidad & 0,43 & 0,00 & 0,18 & 0,16 & 0,60 & 0,17 \\
\hline Observaciones & 53 & 53 & 53 & 53 & 53 & 53 \\
\hline
\end{tabular}

Fuente: elaboración propia con las bases de datos mencionadas en los párrafos siguientes.

La tabla permite analizar las distintas variables del modelo. El gasto público en relación con el PIB oscila entre un mínimo del $19 \%$ y un máximo del $60 \%$ en los últimos años del período. Los estadísticos de normalidad indican el rechazo de la hipótesis nula de distribución normal de la variable siendo realmente platocúrtica. El cociente de deflactores se mantiene bastante cercano a la unidad con un mínimo igual a 0,76 y un máximo de 1,04. En el caso del empleo público se mantiene en los términos comentados anteriormente con un mínimo de 846.000 empleados público y un máximo de 3.250.000. El producto interior bruto per cápita (PIBpc) da un gran salto con un mínimo de 6.848,72 y un máximo de 23.131 euros. La población ha crecido en el período pasando de un mínimo de 31.549 .000 a 46.812.000. Por último, la tasa de desempleo ha evolucionado desde un casi pleno empleo en el período franquista debido a la gran emigración hacia el exterior y a la poca fiabilidad de los datos estadísticos a un valor próximo al $27 \%$. 
En la contrastación empírica se han utilizado en todos los modelos las variables en logaritmos. La variable dependiente en todos ellos es la ratio GP/PIB en euros constantes. En el modelo de hacienda pública se han considerado como variables independientes el PIB per cápita, la población, el cociente entre los deflactores del GP y el PIB y la tasa de paro o desempleo. El período considerado es 1964-2016. Los datos están tomados de las diferentes bases de datos del INE. En todos los casos se han tomado valores reales usando los correspondientes deflactores. Cuando, por la longitud de la muestra, ha sido necesario cambiar de base, este cambio se ha realizado utilizando la unión legal del INE.

En el modelo de elección pública se han utilizado las variables: empleo público, elasticidad impositiva y partidos políticos. La primera para el período 1965-2016 y las otras dos para el período 1980-2016. En el primer caso los datos fueron tomados del INE, de las estadísticas históricas de España de la fundación BBVA y del Boletín estadístico del personal al servicio de las administraciones públicas. Para la segunda variable se ha considerado el tipo medio de gravamen del impuesto sobre la renta tomando datos de la agencia tributaria. La variable partido toma el valor 1 cuando gobierna la derecha (UCD y PP) y el valor cero cuando gobierna la izquierda (PSOE). Dado el corto período democrático no es necesario recurrir a ninguna base de datos.

En la tabla siguiente se tienen los contrastes de raíces unitarias de las variables del modelo.

Tabla 2. Contrastes de raíces unitarias de las variables de los diferentes modelos*

\begin{tabular}{lcccc}
\hline & ADF (VC) & ADFGLS (VC) & PP (VC) & KPSS (VC) \\
\hline LnGPcte/PIBcte & $-0,42(-3,49)$ & $-0,83(-3,18)$ & $-0,94(-3,49)$ & $0,17(0,14)$ \\
\hline LndGP/dPIB & $-3,13(-3,49)$ & $-1,53(-3,18)$ & $-4,53(-3,49)$ & $0,18(0,14)$ \\
\hline LnPoblacion & $-1,83(-2,91)$ & $0,13(-1,94)$ & $-1,50(-2,91)$ & $0,92(0,46)$ \\
\hline LnPibpc & $-1,74(-3,91)$ & $0,45(-1,94)$ & $-2,86(-2,91)$ & $0,96(0,46)$ \\
\hline LnTasaparo & $-2,29(-2,91)$ & $-0,83(-1,94)$ & $-2,60(-2,91)$ & $0,65(0,46)$ \\
\hline Lnemplpub & $-2,55(-2,91)$ & $0,45(-1,94)$ & $-2,48(-2,91)$ & $0,81(0,46)$ \\
\hline$\Delta$ LnGPcte/PIBcte & $-5,69(-2,91)$ & $-5,74(-1,94)$ & $-5,74(-2,91)$ & $0,25(0,46)$ \\
\hline$\Delta$ LndGP/dPIB & $-7,01(-2,91)$ & $-6,52(-1,94)$ & $-7,01(-2,91)$ & $0,49(0,46)$ \\
\hline$\Delta$ LnPoblacion & $-2,14(-1,94)$ & $-2,96(-1,94)$ & $-4,02(-1,94)$ & $0,16(0,46)$ \\
\hline$\Delta$ LnPibpc & $-2,54(-1,94)$ & $-2,40(-1,94)$ & $-3,27(-1,94)$ & $0,36(0,46)$ \\
\hline$\Delta$ LnTasaparo & $-11,33(-2,91)$ & $-11,39(-1,94)$ & $-12,42(-2,41)$ & $0,14(0,46)$ \\
\hline$\Delta$ Lnemplpub & $-5,94(-2,91)$ & $-5,86(-2,91)$ & $-5,97(-2,91)$ & $0,49(0,46)$ \\
\hline
\end{tabular}

Los contrastes son Augmented Dickey-Fuller (ADF), Augmented Dickey-Fuller General Least Squares (ADFGLS), PhillipsPerron (PP) y Kwiatkowski, Phillips, Schmidt y Shin (KPSSS). Entre paréntesis, Valor Critico (VC).

Fuente: elaboración propia. 
Los resultados de los contrastes confirman que todas las variables consideradas son I (1).

En la estimación del modelo de hacienda pública utilizamos como variable dependiente la ratio GP/PIB en logaritmos, las variables independientes utilizadas han sido PIBpc, población, cociente de deflactores y tasa de desempleo todas ellas en logaritmos. Los resultados se presentan en la tabla 3.

Tabla 3. Estimación del modelo de hacienda pública (la variable dependiente es LnGP/PIB)

\begin{tabular}{lcc}
\hline & Coeficiente & Estadístico $t$ \\
\hline LnPIBpc & 0,38 & 2,23 \\
\hline Lnpoblacio & $-0,32$ & $-0,58$ \\
\hline Ln $\mathrm{p}_{\mathrm{g}} / \mathrm{p}_{\mathrm{c}}$ & 0,98 & 2,00 \\
\hline Lntasaparo & 0,21 & 6,94 \\
\hline $\mathrm{C}$ & $-1,83$ & $-0,40$ \\
\hline $\mathrm{R}^{2}$ & 0,90 & \\
\hline
\end{tabular}

Fuente: elaboración propia.

Los resultados son consistentes con un modelo de hacienda pública. El coeficiente de la renta per cápita es mayor que cero, en la línea de la ley de Wagner, con lo que el gasto público es elástico a la renta o bien se puede considerar que es un bien superior. El coeficiente de población es negativo y, aunque no es significativo, su signo indica que una mayor población está asociada con una disminución, en proporción, en la ratio GP/PIB. Es decir, que existen economías de escala en el gasto público español. En el caso de los precios relativos vemos que un aumento en el precio relativo de un $1 \%$ está asociado con una subida del $1 \%$ en la ratio GP/PIB, lo que indica que las subidas de precios son traspasadas totalmente a subidas en los gastos públicos sin reducción en el output real. Esto puede indicar una tendencia de los gastos públicos a subidas basadas en los valores nominales, pero no en los valores reales. Un aumento en el desempleo posibilita, asimismo, una subida en el gasto público derivada del aumento a la subvención a los parados. En la tabla 4 se tienen los resultados a corto plazo derivados del modelo de corrección de error (MCE).

En el MCE, el término de corrección de error tiene el signo esperado y nos indica que la velocidad de ajuste al equilibrio es del $15 \%$ anual. Los cambios en la población no influyen en la evolución del GP, tampoco lo hacen los cambios en la tasa de paro a corto plazo, lo que es esperar dado el intervalo que existe entre 
la situación de paro y el cobro de la prestación. El impacto a corto plazo del PIBpc parece reducir el gasto público, lo que puede indicar un efecto sustitución con el sector privado (fundamentalmente en el consumo privado), pero este efecto se ve anulado en el largo plazo con un coeficiente positivo y significativo.

Tabla 4. Estimación del MCE para el modelo de hacienda pública

\begin{tabular}{lcc}
\hline & Coeficiente & Estadístico $t$ \\
\hline Corrección de error & $-0,15$ & $-2,49$ \\
\hline$\Delta$ LnPIBpc & $-0,63$ & $-2,95$ \\
\hline$\Delta$ Lnpoblacio & 0,44 & 0,71 \\
\hline$\Delta$ Ln $\mathrm{p}_{\mathrm{g}} / \mathrm{p}_{\mathrm{c}}$ & 0,99 & 4,04 \\
\hline$\Delta$ Lntasaparo & 0,02 & 1,63 \\
\hline $\mathrm{C}$ & 0,02 & 2,49 \\
\hline $\mathrm{R}^{2}$ & 0,40 & \\
\hline
\end{tabular}

• El período utilizado es 1964-2016

Fuente: elaboración propia.

Para el modelo de elección pública consideramos las siguientes variables: renta per cápita, tipo impositivo medio (Elast) como una medida exógena de las propiedades de elasticidad ingreso del sistema impositivo, una variable dummy (partido) para representar el partido político en el poder (1 si está la derecha y 0 si está la izquierda), la tasa de desempleo y el número de empleados públicos. En la inclusión de la variable partido se supone que los partidos de derecha favorecen un sector público más pequeño, manteniéndose el resto constante, de manera que un estimador significativo (negativo) de esta variable no necesariamente señala preferencias redistributivas. Sin embargo, puesto que gran parte del gasto público es redistributivo, cualquier reducción en el gasto público total con tal gobierno probablemente implica menos gasto redistributivo. Asimismo, se han incluido la tasa de paro y el número de empleados públicos. La primera como un proxy de los grupos de presión y la segunda en relación al poder de la burocracia en el crecimiento de los gastos públicos. Dadas las limitaciones de las variables Elast y partido (solo están disponibles valores a partir de 1980) se ha realizado una doble estimación: por una parte, la estimación a partir de 1980 incluyendo dichas variables y por otra, desde 1964 considerando el resto de variables.

Los resultados obtenidos se muestran en la siguiente tabla: 
Tabla 5. Modelo de elección pública (la variable dependiente es LnGP/PIB)

\begin{tabular}{|c|c|c|c|c|}
\hline & \multicolumn{2}{|c|}{ Ecuación 1 (1980-2016) } & \multicolumn{2}{|c|}{ Ecuación 2 (1964-2016) } \\
\hline & Coeficiente & Estadístico $t$ & Coeficiente & Estadístico $t$ \\
\hline LnPIBcap & 0,72 & 3,74 & $-0,36$ & $-1,19$ \\
\hline LnTasaparo & 0,25 & 7,12 & 0,16 & 4,31 \\
\hline Lnemplpub & 0,49 & 2,55 & 0,72 & 2,54 \\
\hline Elast & $-0,009$ & $-0,09$ & & \\
\hline Partido & $-0,10$ & $-4,83$ & & \\
\hline C & -4.72 & $-7,11$ & $-3,48$ & $-3,47$ \\
\hline $\mathrm{R}^{2}$ & \multicolumn{2}{|c|}{0,76} & \multicolumn{2}{|c|}{0,92} \\
\hline
\end{tabular}

Fuente: elaboración propia.

En la ecuación 1 se observa que la variable Elast tiene un coeficiente muy pequeño y no es significativa por lo que, si esta variable está bien diseñada y es representativa, no se observaría ilusión fiscal derivada del impuesto sobre la renta. La variable partido tiene el signo negativo esperado, cuando está en el poder un partido de derecha se observa un retroceso en el gasto público. En cuanto a la variable representativa de la burocracia, el signo es positivo y significativo en su coeficiente, aunque el valor es menor que 1 , concretamente 0,49 , lo que indica que una subida de un $1 \%$ en el número de empleados públicos implica un aumento del 0,49\% en el gasto público, considerando todo lo demás constante. Por último, las variables PIB per cápita y Tasaparo tienen signos y magnitudes muy parecidas a las de la ecuación anterior. Al realizar la estimación para el período 1964-2016, el coeficiente del PIBpc cambia drásticamente llegando a ser negativo, aunque no es significativo. Dado que el coeficiente de Tasaparo es prácticamente el mismo, la influencia para el cambio en el gasto público deriva del número de empleados públicos pasando la elasticidad correspondiente de 0,49 a 0,72.

En el modelo a corto plazo obtenemos el siguiente resultado: 
Modelos alternativos para explicar la evolución del gasto público español

Tabla 6. Estimación del MCE para el modelo de elección pública

\begin{tabular}{lcccc}
\hline & \multicolumn{2}{c}{ Ecuación 1 } & (1980-2016) & \multicolumn{2}{c}{ Ecuación 2 (1964-2016) } \\
\hline & Coeficiente & Estadístico $t$ & Coeficiente & Estadístico $t$ \\
\hline Corrección de error & $-0,29$ & $-2,56$ & -0.18 & $-2,13$ \\
\hline$\Delta$ LnPIBcap & $-0,07$ & $-0,25$ & $-0,51$ & $-1,99$ \\
\hline$\Delta$ LnTasaparo & 0,16 & 3,50 & 0,01 & 1,35 \\
\hline$\Delta$ Lnemplpub & 0,16 & 1,38 & 0,57 & 3,11 \\
\hline$\Delta$ Elast & 0,001 & 0,59 & & \\
\hline$\Delta$ Partido & $-0,019$ & $-2,32$ & & 1,69 \\
\hline$C$ & 0,01 & 1,26 & 0,01 & \\
\hline$R^{2}$ & & 0,55 & & \\
\hline
\end{tabular}

Fuente: elaboración propia.

En ambas ecuaciones el coeficiente del ajuste es negativo y significativo, indicando que cada período se corrige el desequilibrio en un $29 \%$ o en un $18,5 \%$. En ambos casos es un ajuste bastante rápido. El comportamiento de las variables cambia mucho en los dos períodos. Si consideramos la muestra completa se observa que tanto la diferencia del PIB como el número de empleados públicos son altamente significativos. La influencia a corto plazo del PIB es negativa lo que indicaría un efecto de sustitución entre bienes públicos y privados mientras que la burocracia influye positivamente en el crecimiento del gasto público. La variable Tasaparo parece tener una gran influencia tanto a corto como a largo plazo lo que indica que las subidas en el gasto inducidas por shocks a corto plazo, por ejemplo, las crisis económicas, pueden tener efectos persistentes en el gasto más allá del shock inmediato. Al igual que en el largo plazo la variable Elast no es significativa mientras que el coeficiente de partido es negativo, lo que indica que, tanto en el corto como en el largo plazo, los partidos de derecha practican políticas restrictivas en relación al crecimiento del gasto público.

En el modelo de administración pública, se consideran los cambios producidos en el comportamiento del sector público español en relación al gasto público. En particular, a partir de la firma de los acuerdos de Maastrich en 1993, el gobierno español adquirió un doble compromiso en relación al déficit y la deuda pública (3 \% y 60 \% del PIB respectivamente) además de la senda ya iniciada con el gobierno del PSOE, y continuada con mayor ahínco por el gobierno del PP, de privatización de empresas públicas. Por tanto, podemos hablar de un cambio en la política fiscal que se convierte en restrictiva en relación al déficit y, por tanto, al gasto público. 
Se utiliza una variable ficticia indicando un cambio en la tendencia. Se espera un signo negativo en dicha variable. Como variable de control se utiliza Lntasaparo al igual que en el modelo anterior.

Tabla 7. Modelo de administración pública (la variable dependiente es LnGP/PIB)

\begin{tabular}{lcc}
\hline & Coeficiente & Estadístico t \\
\hline NPM & 0,001 & $-1,34$ \\
\hline Lntasaparo & 0,34 & 11,73 \\
\hline $\mathrm{C}$ & $-1,87$ & $-27,66$ \\
\hline $\mathrm{R}^{2}$ & 0,78 & \\
\hline
\end{tabular}

Fuente: elaboración propia.

El resultado nos indica un cambio en la pendiente que no es significativo. En el corto plazo se tiene el siguiente resultado:

Tabla 8. Estimación del MCE para el modelo de elección pública

\begin{tabular}{lcc}
\hline & Coeficiente & Estadístico $t$ \\
\hline Corrección de error & $-0,07$ & $-1,11$ \\
\hline$\Delta$ NPM & $-0,04$ & $-2,88$ \\
\hline$\Delta$ Lntasaparo & 0,01 & 0,70 \\
\hline$C$ & 0,03 & 3,83 \\
\hline $\mathrm{R}^{2}$ & 0,22 & \\
\hline
\end{tabular}

Fuente: elaboración propia.

En el corto plazo, aunque con un coeficiente muy bajo, la variable que indica el cambio de política sí es negativa y significativa, con lo que podemos inferir que el cambio de política ha influido en un menor valor de la tendencia en el corto plazo, aunque no se pueda inferir ningún cambio en el corto plazo. Para construir un modelo combinado, se parte del modelo de hacienda pública y le vamos añadiendo variables. Nuestro criterio fundamental es el poder explicativo del modelo, medido por el $R^{2}$ 
Tabla 9. Modelo combinado

\begin{tabular}{lccccc}
\hline & Ecuación & Ecuación 2 & Ecuación 3 & Ecuación 4 & Ecuación 5 \\
\hline LnPIBpc & $0,38(2,23)$ & $-0,45(-1,96)$ & $-0,11(-0,65)$ & $0,34(3,16)$ & $0,34(3,09)$ \\
\hline Lnpoblacio & $-0,32(0,58)$ & $-1,17(-2,45)$ & $-1,2(-3,03)$ & $-0,77(-3,60)$ & $-0,73(-3,66)$ \\
\hline Ln $\mathrm{p}_{\mathrm{g}} / \mathrm{p}_{\mathrm{c}}$ & $0,98(2,00)$ & $1,2(3,37)$ & $-0,85(-1,68)$ & $-0,29(-1,06)$ & $-0,33(-1,18)$ \\
\hline Lntasaparo & $0,21(6,84)$ & $0,09(2,91)$ & $0,19(6,15)$ & $0,24(12,91)$ & $0,25(14,18)$ \\
\hline Lnemplpub & & $1,09(4,32)$ & $0,71(2,68)$ & $0,14(0,93)$ & $0,12(0,84)$ \\
\hline Elast & & $-0,15(-1,69)$ & $-0,07(-1,46)$ & \\
\hline Partido & & & & $-0,07(-6,74)$ & $-0,08(-7,40)$ \\
\hline $\mathrm{C}$ & $-1,83(-0,40)$ & $7,30(1,74)$ & $7,32(2,18)$ & $2,37(1,28)$ & $1,92(1,15)$ \\
\hline $\mathrm{R}^{2}$ & 0,90 & 0,95 & 0,69 & 0,82 & 0,80 \\
\hline
\end{tabular}

Fuente: elaboración propia.

Se ha considerado el modelo de hacienda pública al que se van añadiendo las diferentes variables de elección pública. Se observa cómo al añadir la variable representativa de la burocracia el ajuste mejora ostensiblemente y las variables son todas significativas. La variable población indica ahora que existen economías de escala (el coeficiente es mayor que 1) en la provisión de bienes públicos. Por su parte la variable que nos indica el precio relativo nos dice que una parte del crecimiento del PIB se debe a la existencia de precios mayores en la administración pública de acuerdo con la hipótesis de disparidad de Baumol. Cuando se introducen las variables Elast y partido, el ajuste empeora, los coeficientes del resto de variables conservan el signo en la ecuación 3 mientras en la 4 y la 5 se producen varios cambios. Sin embargo, la variable precio relativo pierde su significatividad mientras la variable Elast no es significativa en ninguna de las ecuaciones 3 y 4 . Por su parte la variable partido es significativa en ambas ecuaciones y tiene el signo esperado. En la ecuación 5 se mantienen el signo y los valores de los coeficientes de todas las variables excepto Ln $\mathrm{p}_{\mathrm{g}} / \mathrm{p}_{\mathrm{c}}$ que deja de ser significativa mientras la variable partido tiene el mismo valor. En consecuencia, parece que el mejor ajuste se produce considerando la ecuación 2. Es decir, el modelo de hacienda pública añadiendo la variable representativa de la burocracia.

En el corto plazo se tiene el siguiente resultado: 
Tabla 10. Estimación del MCE para el modelo de Elección Pública

\begin{tabular}{lccccc}
\hline & Ecuación 1 & Ecuación 2 & Ecuación 3 & Ecuación 4 & Ecuación 5 \\
\hline Corrección de error & $-0,15(-2,49)$ & $-0,15(-1,89)$ & $-0,39(-3,41)$ & $-0,76(-5,09)$ & $-0,77(-5,75)$ \\
\hline$\Delta$ LnPIBpc & $-0,63(-2,95)$ & $-0,52(-2,45)$ & $0,31(0,91)$ & $-0,07(-0,24)$ & $-0,22(-0,79)$ \\
\hline$\Delta$ Lnpoblacio & $0,44(0,71)$ & $-0,18(-0,30)$ & $-0,18(-0,30)$ & $-0,73(-1,27)$ & $-0,81(-1,67)$ \\
\hline$\Delta$ Ln $\mathrm{p}_{\mathrm{g}} / \mathrm{p}_{\mathrm{c}}$ & $0,99(4,04)$ & $1,34(5,55)$ & $0,46(1,54)$ & $0,58(2,20)$ & $-0,33(-1,18)$ \\
\hline$\Delta$ Lntasaparo & $0,02(1,63)$ & $0,02(1,76)$ & $0,28(5,33)$ & $0,25(5,66)$ & $0,24(5,67)$ \\
\hline$\Delta$ Lnemplpub & & $0,54(3,55)$ & $0,41(3,14)$ & $0,25(2,25)$ & $0,25(2,48)$ \\
\hline Elast & & & $0,001(0,04)$ & $-0,00(-0,18)$ & \\
\hline Partido & & & & $-0,04(-2,73)$ & $-0.04(-3,34)$ \\
\hline C & $0,02(2,49)$ & $0,01(1,08)$ & $-0,01(-0,73)$ & $0,01(0,75)$ & $0,01(1,08)$ \\
\hline R & 0,40 & 0,49 & 0,56 & 0,66 & 0,67 \\
\hline
\end{tabular}

Fuente: elaboración propia.

A corto plazo se observa que el coeficiente de corrección de error es negativo y significativo en todos los casos, lo que indica que existe una tendencia hacia el equilibrio cualquiera que sea la ecuación que se considere. Las variables PIBpc y población no son significativas a corto plazo, lo que indica que su influencia en el crecimiento del GP se produce en el largo plazo, pero en el corto no se producen cambios al modificar dichas variables. No ocurre lo mismo con las variables cociente de los deflactores del GP y el PIB, Tasaparo y Emplpub que influyen en los cambios a corto plazo del GP/PIB de forma bastante notoria. En particular parece que gran parte del crecimiento del GP a corto plazo viene determinado por el precio relativo de los bienes públicos. El aumento de los empleados públicos influye tanto en el corto como en el largo plazo y la influencia del número de desempleados parece ser mayor a corto que a largo plazo. No parece haber ninguna influencia ni a corto ni a largo plazo de la elasticidad impositiva, aunque sí del partido político en el poder cuyo coeficiente también es negativo y significativo en el corto plazo indicando que las restricciones en el gasto de los partidos de la derecha se producen de forma casi simultánea a su llegada al poder político.

\section{CONCLUSIONES}

En este trabajo se han considerado tres modelos explicativos de la evolución del gasto público aplicados al caso español: hacienda pública, elección pública y administración pública. En estos modelos se mezclan variables explicativas desde el lado de la demanda y de la oferta. 
En el modelo de hacienda pública se consideran como variables explicativas el PIB per cápita, la población, el cociente entre los deflactores del GP y el PIB y la tasa de desempleo. Los resultados, que corroboran lo esperado teóricamente, indican que un aumento de la renta per cápita provoca, en la línea de la ley de Wagner, un aumento en el gasto público, por el contrario, un aumento en la población está asociado con una disminución, mientras que las subidas de precios son traspasadas en su totalidad a subidas en el gasto sin reducción en el output real. Por último, un aumento en el desempleo posibilita asimismo un aumento en el gasto público.

En el modelo de elección pública se consideran como variables la renta per cápita, el tipo impositivo medio, una variable dummy referida al partido político en el poder, la tasa de paro y el número de empleados públicos. La variable representativa de la elasticidad ingreso del sistema impositivo no es significativa.

En cuanto al modelo de administración pública no se observa influencia de la variable elegida en el comportamiento del gasto público. Finalmente se ha construido un modelo combinado partiendo del modelo de hacienda pública añadiéndole variables. El mejor comportamiento se observa cuando se añade a dicho modelo la variable representativa de la burocracia.

\section{BIBLIOGRAFÍA}

Alcaide, Julio. (1988). El gasto público en la democracia española: los hechos. En: Papeles de Economía Española, n. ${ }^{\circ}$ 37, p. 2-41.

Aranson, Peter y Ordeshook, Peter. (1977). Incrementalism, the fiscal illusion and the growth of government in representative democracies. Miami: University of Miami, $80 \mathrm{p}$.

Bergstrom, Theodore y Goodman, Robert. (1973). Private Demands for Public Goods. En: American Economic Review, vol. 63, n. 3, p. 280-296.

Borcherding, Thomas; Bush, Winston y Spann, Robert. (1977). The effects on public spending of the divisibility of public outputs in consumption, bureaucratic power and the size of the tax-sharing group. En: Borcherding, Thomas. (Ed.). Budgets and Bureaucrats: The Sources of Government Growth. Ann Arbor: Umi Research Pr, p. 211-228.

Borcherding, Thomas. (1985). The causes of government expenditure growth: A survey of the U.S. evidence. En: Journal of Public Economics, vol. 28, n. 3, p. 359-382. Doi: doi. org/10.1016/0047-2727(85)90065-9

Borcherding, Thomas y Deacon, Robert. (1972). The demand for the services of non-federal governments. En: American Economic Review, vol. 62, n. ${ }^{\circ}$ 5, p. 891-901.

Bush, Winston y Denzau, Arthur. (1977). The voting behavior of bureaucrats and public sector growth. En Borcherding, Thomas (Ed.). Budgets and Bureaucrats: The Sources of Government Growth. Ann Arbor: Umi Research Pr, p. 90-99. 
Comin, Francisco y Díaz, Daniel (2005). Sector público administrativo y estado del bienestar. En: Tufannel, Xavier y Carrearas Albert. Estadísticas Históricas de España. Fundación BVA. Madrid, p.873974.

Courakis, Anthony; Moura-Roque, Fátima y Tridimas, George. (1993). Public expenditure growth in Greece and Portugal: Wagner's law and beyond. En: Applied Economics, vol. 25, n. ${ }^{\circ}$ 1, p. 125-134. Doi: 10.1080/00036849300000121

Cullis, John y Jones, Philip. (2009). Public Finance and Public Choice. Analytical Perspectives. Oxford: University Press, 560 p.

Gemmell, Norman. (1990). Wagner's Law, Relative Prices and the Size of the Public Sector. En: Manchester School of Economics and Social Studies, vol. 58, n. ${ }^{\circ}$ 4, p. 361 377. Doi: / $\overline{\mathrm{abs}} / 10.1111 / \mathrm{j} .1467-9957.1990 . t b 00428 . x$

Gemmell, Norman. (Ed.). (1993). The Growth of the Public Sector: Theories and International Evidence. Aldershot: Edward Elgar Publishing, 261 p.

Gemmell, Norman; Gill, Derek y Nguyen, Loc. (2016). Explaining the Size of the State in New Zealand, 1972-2014. Wellington: Victoria University of Wellington, $36 \mathrm{p}$.

Hood, Christopher. (1991). A Public Management for All Seasons? En: Public Administration, vol. 69, p. 3-19.

Jaén-García, Manuel. (2004). Evolución contemporánea del gasto público en España. Almería: Universidad de Almería, 240 p.

Jaén-García, Manuel. (2016). Public expenditure and deficit in Spain (1958-2014). En: Semestre Económico, vol. 19, n. ${ }^{\circ}$ 40, p. 17-52. Doi: doi.org/10.22395/seec.v19n40al.

Jaén-García, Manuel. (2017). A Demand Determinants Model for Public Spending in Spain. En: International Journal of Economics and Financial Issues, vol. 7 n,o 4, p. 372-386.

Jordana, Jacint y Ramío, Carles. (2005). Gobierno y Administración. En: Tafunell, Xavier y Carreras Albert. Estadísticas Históricas de España .Madrid: BBVA, p.973-1026.

Lowery, David y Berry, William. (1983). The Growth of Government in the United States: An Empirical Assessment of Competing Explanations. En: American Journal of Political Science, vol. 27, n. ${ }^{\circ}$ 4, p. 665-694. Doi: 10.2307/2110888

Meltzer, Allan y Richard, Scott. (1978). Why Government Grows (and Grows) in a Democracy. En: Public Interest, vol. 52, p. 111 118.

Meltzer, Allan y Richard, Scott. (1981). A Rational Theory of the Size of Government. En: Journal of Political Economy, vol. 89, n. 5, p. 914-927.

Meltzer, Allan y Richard, Scott. (1983). Tests of a rational theory of the size of government. En: Public Choice, vol. 41, n. ${ }^{\circ}$ 3, p. 403-418.

Ministerio de Hacienda y Administraciones Públicas (varios años): "Boletín estadístico del personal al servicio de las Administraciones Públicas". http://www.minhafp.gob.es/es ES/ Areas\%20Tematicas/funcion\%20publica/Paginas/boletin _ rcp.aspx. 
Ministerio de Hacienda y Administraciones Públicas (varios años). "Estadísticas de los declarantes del impuesto sobre la renta". https://www.agenciatributaria.es/AEAT.internet/datosabiertos/ catalogo/hacienda/Estadistica_de _los_declarantes_del_ IRPF.

Mueller, Dennis. (2003). Public Choice III. Cambridge: Cambridge University Press, 768 p.

Niskanen, William. (1968). The Peculiar Economics of Bureaucracy. En: American Economic Review, vol. 58, n. ${ }^{\circ}$ 2, p. 293-305.

Niskanen, William. (1971). Bureaucracy and Representative Government. Nueva Jersey: Transaction Publishers, $251 \mathrm{p}$.

Neck, Reinhard y Schneider, Friedrich. (1988). The Growth of the Public Sector in Austria: An Exploratory Analysis. En: Contributions to Economic Analysis, vol. 171, p. 231-263. Doi: doi. org/10.1016/B978-0-444-70426-9.50015-9

Pesaran, Hashem. (1997). The Role of Economic Theory in Modelling the Long Run. En: Economic Journal, vol. 107, n. ${ }^{\circ} 440$, p. 178-191.

Pesaran, Hashem y Shin, Yongcheol. (1999). An Autoregressive Distributed Lag Modelling Approach to Cointegration Analysis. En: Strom, Steiner (Ed.). Econometrics and Economic Theory in the 20th Century: The Ragnar Frisch Centennial Symposium. Cambridge: Cambridge University Press, p. 371-413.

Pesaran, Hashem y Smith, Ron. (1995). Estimating long run relationships from dynamic heterogeneous panels. En: Journal of Econometrics, vol. 68, p. 79-113. Doi: doi.org/10.1016/0304-4076 (94)01644-F

Pollitt, Christopher. (1995). Justification by Works or by Faith? Evaluating the New Public Management. En: Evaluation, vol. 1, n. 2, p. 133-154. Doi: doi.org/10.1177/135638909500100202

Pommerehne, Werner y Schneider, Friedrich. (1978). Fiscal Illusion, Political Institutions and Local Public Spending. En: Kyklos, vol. 31, n. ${ }^{\circ}$ 3, p. 381-408.

Tridimas, George. (1992). Budgetary Deficits and Government Expenditure Growth: Toward a More Accurate Empirical Specification. En: Public Finance Quarterly, vol. 20, n. ${ }^{\circ}$ 3, p. 275 297. Doi: $10.1177 / 109114219202000301$

Valle, Victorio. (1996). La hacienda pública de la democracia española: principales rasgos. En: Papeles de Economía Española, n. ${ }^{\circ}$ 68, p 2-9.

Wagner, Richard. (1976). Revenue structure, fiscal illusion and budgetary choice. En: Public Choice, vol. 25, 